\title{
Strategies for Transition to Third Generation Cellular Communication in Sri Lanka
}

\author{
M. R. M. Hazary and A. T. L. K. Samarasinghe
}

\begin{abstract}
The mobile market is currently in the phase of being restructured. The introduction of third generation (3G) networks incurs to high expenditure. These expenses have to be compensated with revenues from successful applications and mobile services, which contribute to $a$ positive Return on Investment (ROI). Researchers' ultimate objectiveis to understand the user acceptance of 3G services in Sri Lanka and formulation of strategies to make $3 \mathrm{G}$ a reality in Sri Lanka. Research findings shows that there is a market acceptance for 3G services in Sri Lanka and the service providers are technically capable of absorbing the technology in to their systems. Further implementation should prioritize on the delivery on benefits to customers rather than clever technology.
\end{abstract}

Key Words: Third generation (3G), Mobile market, restructuring, Return on Investment (ROI), technology, Strategies

\section{Introduction}

\subsection{Background}

Economic growth, the pace of technical change, and the element of mobility in modern lifestyles, will continue to drive demand for mobile services. Mobile services will grow in number and variety, and will come to include most of that is mainly available from fixed access today. In the year 2001, number of mobile subscribers exceeded the number of wired subscribers in the world [1]. Due to the comparatively low cost of the mobile communication equipment and the service availability while on the move the digital communication is expected to be the most accepted method of communication.

The Third Generation (3G) technologies are turning phones and other devices into multimedia players, making it possible to download music and video clips. It uses Wideband Code Division Multiple Access (WCDMA) technology to transfer data over its networks. W-CDMA sends data in a digital format over a range of frequencies, which makes the data move faster, but also uses more bandwidth than digital voice services.

$3 \mathrm{G}$ is considered, high-speed or broadband mobile Internet access, and in the future $3 \mathrm{G}$ networks are expected to reach speeds having more than $2 \mathrm{Mbps}$.

In Sri Lanka there are five mobile operators. All existing operators started their business operations in late 1980'sor early 1990's, but some are still new to the business with regard to the new technologies. But within few years some operators were able to reach the standard of developed country operator's technology.

It is decision time, as many mobile operators must now commit to $3 \mathrm{G}$ rollouts and launches. Operators need to beware of simply following the launch strategies of others, many of which may have serious consequences.

\subsection{Research Problem}

Researchproblem specificallyisfor"strategiesfor transition to third generation cellular communication in Sri Lanka". The mobile market is currently in the phase of restructuring. The introduction of the universal mobile telecommunications system (UMTS) network was related to high expenditures. These expenses have to be compensated with revenues from successful applications and mobile services, which contribute to a positive return on investment (ROI) in the nearest future. History reveals many successful and non-successful mobile services. On the one hand, mobile services liketrafficnavigation or videoconference services are still waiting for their economic breakthrough. On the other hand, multiple mobile services like SMS(short message service), ring tone and $\log 0$ download services can be found, which have not

M R M Hazary,BSc Eng., AIESL, MIEEE, Progranmme Mannger, - Access Network, Dialog Telekom PLC.

Eng. A TL KSamarasinghe, BSc Eng., (Moratuwa),M.B.A.(SriJ)C.Eng.,

MIE(SrLanka), Head of Department, Dept. of Electronic and

Telecommunication, University of Moratuiva 
fawn predicted to have a strong economic success. II becomes obvious that one of the most important Intom tor Ihe success or failure of mobile services in the user acceptance.

Ill on leı to minimize the barriers to success, a isbstantial and in-depth consideration of the IIIIial fur Iors lor the user acceptance is iiit masary.

\section{T Projecl Objectives}

Dilicilives of the project are identified by cons. leing industry background and research jublem

f. In assess the market acceptance of $3 \mathrm{G}$ bers iues in Sri Lanka

I r identify best practices for absorption and adaptation of $3 \mathrm{G}$ services

(1) I.....usess the conduciveness of Immediate I in ironment of Transferor and Transferee for Smooth Transfer of 3G Technology

$4 \quad$ I...... ommend strategies for transition to Ihird Generation Cellular Communication in Eiri Lank.

\section{1, Illerature Review}

\section{1.) Iniroduction to Mobile Communication Ivolution}

I tlislar mobile communications is an indípensable tool for everyday lives of millions bi peoplertiomul the world. Mobile telephony MI undergone several evolutionary stages from I Iethical perspective. In the beginning, first ilitiefalion ( $\mathrm{GG}$ ) mobile technologies formed the avallable service provider networks. These line kafe Advanced Mobile Phone System (AMPS) fa Nili Amet ic a, Total Access Communication Liviviou (TACS) in the United Kingdom, and Norilde Mobile Telephony (NMT) in the Nordic fianiales [2] In the lirst generation network, the Limbiant application was speech. Apart from ini mother service was available for its users. I hit lo each system being proprietary, there was Iit common approach to support roaming Lielwem thesesystems. Subsequently, under the falionalge of the European Telecommunications hianiofili Institute (ETS1), the second generation
(2G) mobile telecommunication system, namely the Global System for Mobile communication (GSM) was introduced. This technology paved the way to introduce in addition to voice telephony, text messaging and international roaming services. It also introduced circuit switched data as well. While GSM was widely accepted in Europe, Asia, Latin America and Africa, North America came up with its own technology standards for its $2 \mathrm{G}$ rollout. These were the Code Division Multiple Access (CDMA) based IS-95 and the Time Division Multiple Access (TDMA) based IS-136. Japan also came up with its own $2 \mathrm{G}$ standard, namely the Personal Digital Network (PDC) network. Some enhancements were made to compliment GSM later on, namely the General Packet Radio Service (GPRS) and Enhanced Data rates for GSM Evolution (EDGE) to avail Internet Protocol(IP) based packet switched data overGSM networks. While GPRS was designated as $2.5 \mathrm{G}$, EDGE was considered as $2.75 \mathrm{G}$. With the advent of $2 \mathrm{G}$ networks throughout the world, $1 \mathrm{G}$ network ceased to exist [2].

\subsection{Mobile Communication Market}

According to the statistics from International Telecommunication Union (ITU) the world telecommunication market for W-CDMA and GSM is depicted below in Figure 1[3]. There has been a clear growth for W-CDMA, in other words 3G, from Q2 2006 to Q2 2007. The absolute value for the number of subscribers for W-CDMA subscribers is very low as W-CDMA is at inception level (lowest line).

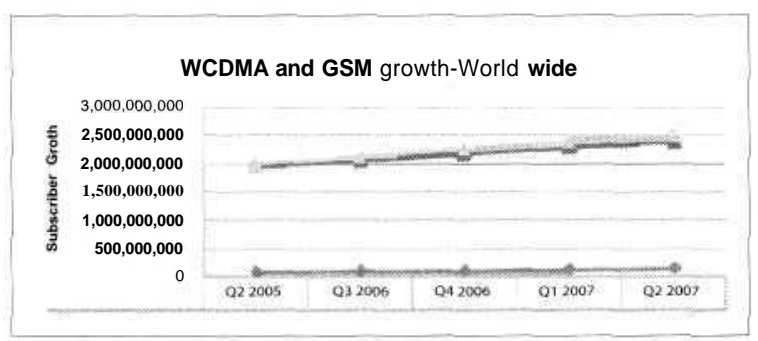

Figure 1:W-CDMA and GSM Growth-World Wide

The Asia Pacific region takes the second highest share of world $3 \mathrm{G}$ market as per the Figure 2 below. The Cellular Operators Association of India claims that for every one percent increase in telephone penetration there is a three percent increase in Gross Domestic Product (GDP) [4]. 


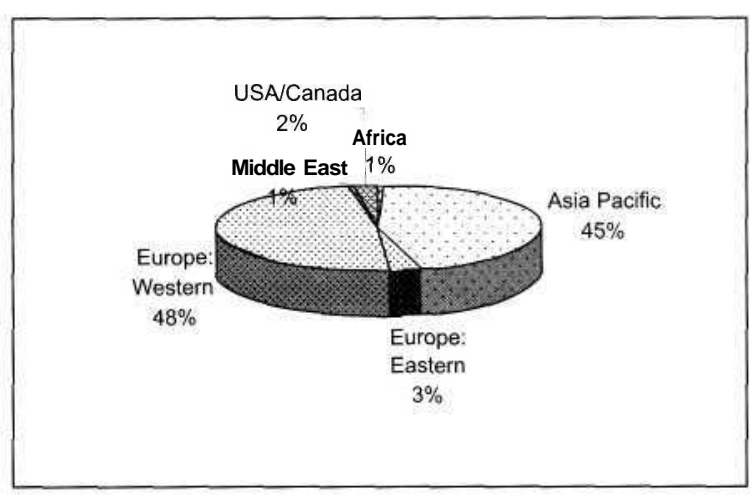

Figure 2:Regional WCDMA Subscribers-Q22007

\subsection{Higher Bandwidth Application Usage}

ABI Research, forecasts that by 2011 global revenues from Over The Air (OTA) downloads of full-track music will be US\$9.3 billion, a healthy jump from worldwide revenues of US\$12.4 million in 2004[5].
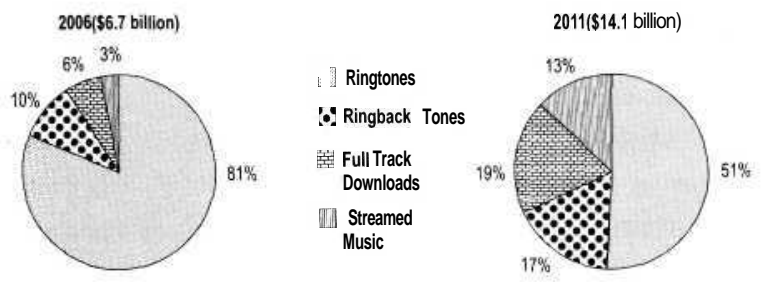

Figure 3: Ring Tone Revenue

However, ABI warns that those interested in gaining a share of these revenues will need to be aware of five Pre-requisites. One of the Prerequisites is "A $3 \mathrm{G}$ network capable of delivering the product."

According to a recent survey, 80 percentage of mobile phone users played games at least once a week, while 34 percent indicated they played every day [5].

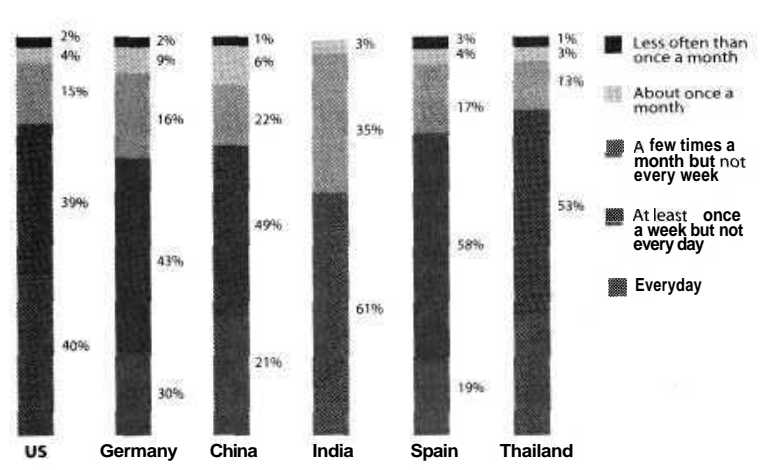

Figure4: Gammingby Region
While these strict guidelines might be applicable to regions where PC-based fixed Internet access is already widespread, emerging markets could well follow the i-mode model that NTT DoCoMo pioneered in Japan, where fixed Internet penetration is 67 percent, while mobile Internet penetration is over 73 per cent, according to the MIC White Paper 2006.

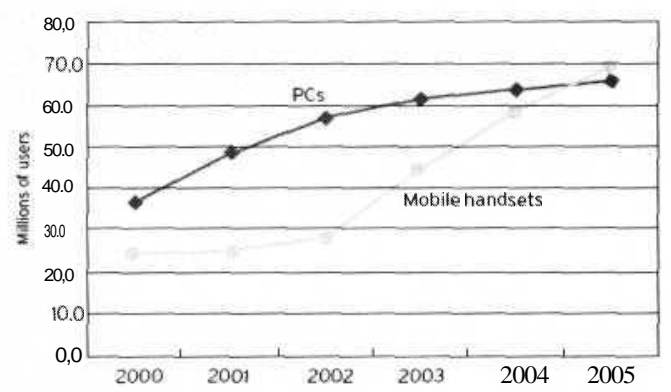

Figure 5:Internet Users by Type of Device in Japan

Today, over 90 percent of DoCoMo's 52 million users subscribe to its "i-mode" mobile Internet service, and over 60 percent of them access the mobile Internet on a daily basis, with the PC being the secondary preferred platform.

\subsection{Sri Lankan Telecommunication Context}

The constant improvement in the country's socio economic well being together with liberalized policies of telecommunication sector in Sri Lanka has made the telecommunication market attractive. Introduction of competition, careful selection of investors, better policies governing the distribution of service and investments to cover most of the country map has taken the telecommunication service up to rural area.

Table 1 : Subscriber Penetration for Fixed and Cellular Telecom Industry in Sri Lanka

\begin{tabular}{|l|l|}
\hline Total number of Fixed phones & $2,086,774$ \\
\hline Tele-density (Fixed Phones per 100 inhabitants) & 10.0 \\
\hline Number of Cellular Mobile Subscribers & $5,958,685$ \\
\hline Mobile Phones per 100 people & 30.0 \\
\hline Total Telephone Subscribers (Fixed \& Cellular) & $8,045,459$ \\
\hline Total Tele-density (Fixed \& Cellular) & 40.0 \\
\hline Internet \& Email Subscribers & 150,000 \\
\hline
\end{tabular}

As per the Telecommunication Regulatory Commission of Sri Lanka (TRCSL) statistics mobile penetration is very high compared to the fixed line. 


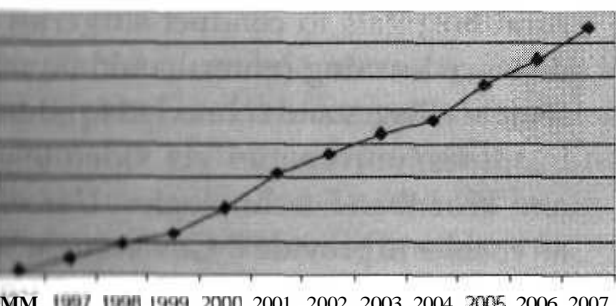

MM 1937 เพติ 199920002001200220032004200520062007

Year

Піяшп <. I mil and Internet Growth 1996-2006

A* pei the TRCSL records the subscribers for I ...... nel Email is very less counts to 150,000 , whic It Itiell , ommunicates the potential for the dato aervice in the Sri I ankan market. The Figure 6 illuatrates the growth of internet and e-mail user frofI Ivero 2000[6]. Local mobile and fixed

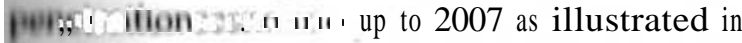
Hifun. I he:comparison between fixed and enllular subscribers is also described. The hinnifion observation made from the above mrayh In the approximate exponential growth in Eiliulai aubscribers in Sri Lanka. The fixed line nbacriber are saturating, while cellular nubscribers are increasing exponentially [6].

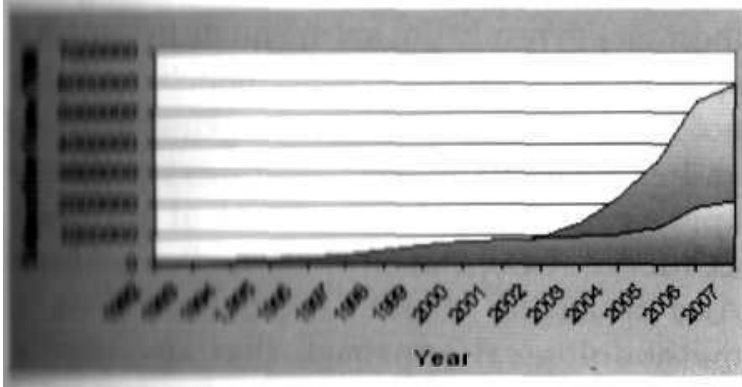

Vinuis 1 ; Vixed mobile penetrationSri Lanka

In a yery short span of time GSM (Global System fir Mobile i emmunications) technology has played an important role, and it has surpassed the tixen telephony subscribers in end of year $200316 \mid$. Ihe supporting factors for the wimential growth of mobile subscribers would he the increase In per capita income as illustrated

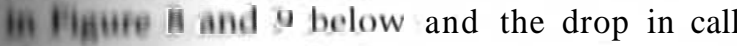
harieh over $A$ period of time (International Girect Dialing and Local) due to the fierce внмyeition rtiul liberalization of monopoly with hit LanM Telecom (SLT) on International Direct Balime (IDD).

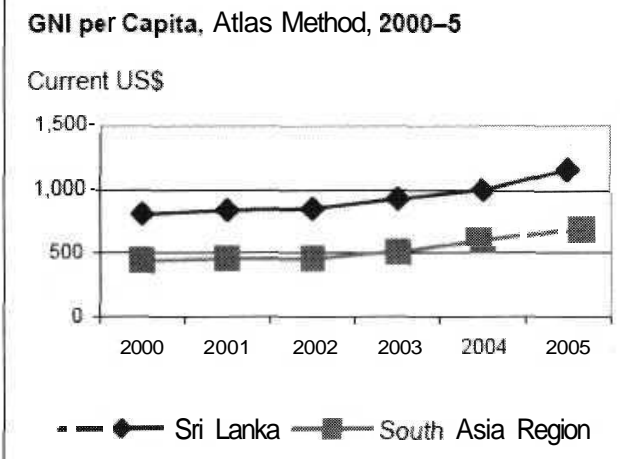

Figure 8 : Per Capita income compared with South Asia region

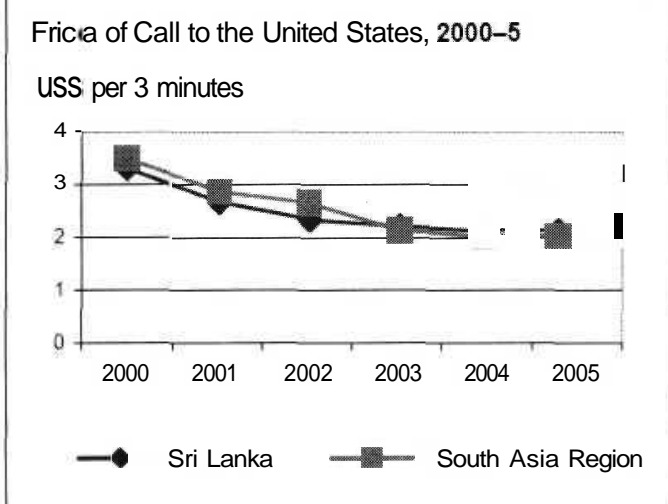

Figure 9 : Price of Call to US

Even the Sri Lankan national economy is influenced by the mobile telecommunication development. Sri Lankan economy has recorded a growth since year 2001 as shown in Figure 10. The main driving forcebehind this growth is the growth in service sector in Sri Lanka.As in the previous 4 years, growth in 2005 was driven by that part of the services sector not related to tourism (i.e, import-related trade, mobile telephony, and financial services) [7]. The telecom sector is the largest in terms of Foreign Direct Investment (FDI) and moreover the sector has made over 20 percent contributions to GDP growth since 2001 and made up 6.6 percent of total economic growth in Sri Lanka in 2005 [8].

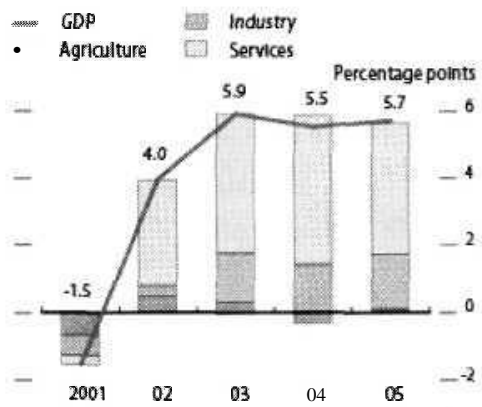

Figure 10 : Contribution to GDP Growth-Sri Lanka 
With the major milestones of the telecommunications industry in Sri Lanka, some mobile operators in Sri Lanka have implemented new technologies and applications first time in South Asia. One classic example is implementing GPRS network first time in South-Asia by a Sri Lankan mobile operator- Dialog Telekom Ltd. Another example is trial launch of a $3 \mathrm{G}$ mobile technology by the same company for the first time in South-Asia. Other than major technologies, local operators have contributed to major advancement of the mobile applications industry.

\subsection{Benefits of $3 \mathrm{G}$ to Sri Lanka}

\section{Consumer Perspective}

Even though it may seem that direct benefits of $3 \mathrm{G}$ would flow to the top end of the market, a careful evaluation shows that majority of the existing and potential consumers would benefit from 3G. Some of such benefits are listed below;

a. $\quad 3^{\text {rd }}$ Generation services involve Multi Media Communication (Voice, Picture, and Text) and this would help to enhance the quality of communication, commercial efficacy and standard of living of the Sri Lankan consumer.

b. Sri Lanka is lagging behind in regional benchmarks in terms on internet penetration mainly due to poor Personal Computer (PC) penetration and high cost associated with telecommunications services required for internet connectivity.

\section{National I Industry Perspective}

Following benefits would accrue to the country as a result of proposed Implementation of $3 \mathrm{G}$ services in Sri Lanka.

a. $3 \mathrm{G}$ licensing will attract FDI to the country. 3G will facilitate network expansion and growth in telecom penetration. Increased penetration \& excellent communications infrastructure would help attract new investments to the country.

b. Deployment of $3 \mathrm{G}$ would help to enhance Public Infrastructure and standard of Living of Sri Lankans. For example Video Calling would enable use of TELE MEDICINE by rural hospitals to conduct surgeries whilst distance learning centers could be set up in remote villages and connected to educational institutes/universities via video telephony and broadband technologies. Use of $3 \mathrm{G}$ as an enabler to provide E-Government Services. and thereby cut down on travel time and costs of the Sri Lankan public [6]

2.6 Acceptance Model for the Analysis and Evaluation of Mobile Services

The user acceptance is more and more regarded as a critical success factor for mobile services. According to the frame work developed for user acceptance, Michael Amberg, Markus Hirschmeier and Jens Wehrmann (2004) [9]. Compass Acceptance Model (CAM) helps to verify the perception concerning user acceptance or to understand the user (types of users and behavior patterns) and the implication of service design better. The insights assist in considering explicitly the user acceptance in the design of a mobile service. Most acceptance models concentrate on some aspects of user acceptance and provide a detailed analysis structure for these aspects. An analysis is very time-consuming and the in-depth results are not adequate to improve application design. The existing models were also not designed to integrate the acceptance analysis and evaluations into an overall methodical approach for the development of services. COMPASS (COoperation Model for Personalized And Situation dependent Services) is a methodological approach that specifies a conceptual framework and the fundamental requirements for a service platform to cooperatively develop and provide situation dependent mobile services. This approach pays attention to the special market situation and considers legal, economical and technical conditions, which are relevant for developing and providing mobile services. Such specialized approaches may affect productivity and service quality positively and finally lead to higher usage intensity of mobile services and increase the revenue of service providers and mobile network operators.

\section{The Compass Acceptance Model}

The Compass Acceptance Model is an instrument designed for the analysis and evaluation of the 
Wher actipl une ol mobile services. TheMeta atiution (7) igure 11) of the Compass Acceptance Alutel consists of the complementary and arheghcrial categories Benefits and Efforts and Alerier anil General ( onditions of. Services:

IIomeiii and I fforts: Which include all positive and negorite aspec Is lorthe user acceptance. The talegorization in Benefits and Efforts is confirmed IUIman models for user acceptance as a fintorontal cognitive consideration in human dec inim processes.

Eervice and General Conditions of Services: The proclur I speritic aspects of user acceptance are abiaumed in the category Service. In the complementary category Genera! Conditions of Aeraic... all surrounding social, cultural, exвnemical and technical conditions are considered, which also play an important role for tis user acceptance of a service.

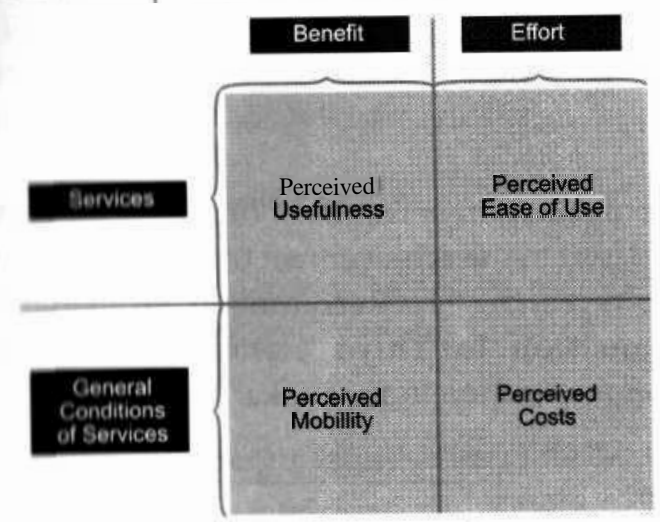

Higure 11 : Dimensions of the Compass Acceptance Model

These categories lead to four dimensions that are relevant for an in-depth analysis of user asceptance:

Pen eived Usefulness, Perceived Ease of Use, Perceived Mobility and Perceived Costs

(Perceived) Usefulness: The dimension build by the categories Benefits and Service describes the perceived usefulness of a service. Indicators measuring this dimension might be perceived information quality and quantity or conformity ol expectations.

(Perceived) Ease of Use: The dimension characterized by the categories of Service and Ifforts can be identified with the perceived ease (1) use, the degree to which a person believes that using a particular service would be free of effort . In this context, the ease of use can be interpreted as an effort for the use of a service. Indicators measuring this dimension are for example the ease of configuration or first log-in, overall handling and menu navigation.

(Perceived) Mobility: The categories Benefits and General Conditions of Services lead to the dimension of Perceived Mobility. The consideration of the general conditions of a service is important in the context of mobile services as their acceptance highly depends on the economical, social and technological perspectives. Indicators measuring this dimension might be network coverage, accessibility, technologicalinfrastructure etc.

(Perceived) Costs: This dimension is formed by the categories of Efforts and General Conditions of Services. Mobile services can lead to profound changes in technological and social systems causing monetary and non-monetary costs. Costs transparency, data security and health risks are considered as appropriate indicators. These four dimensions focus on the subjective perception. This emphasizes the valuation of a service by the end user's subjective point of view.

Researchers have adopted all four variable of Compass Acceptance model namely[9];

\section{a. Perceived Usefulness \\ b. Perceived Ease of Use \\ c. Perceived Mobility and \\ d. Perceived Costs}

Researchers are strongly agreeing with the Compass acceptance model and have added two more variables to make the framework more acceptable, in Sri Lankan context.

Customer attitude: There are some characteristics that are specific to the Nation, values, which will decide the success or failure of certain changes to the society. Customer attitude towards change is one such criteria and researchers have investigated into the variable from the point of view of willingness to change, learn and experience new services.

Income level: Similarly, the income level is also another important dimension for the developing countries. The Compass acceptance model was developed in the European region and the 
developers might of least concern about the income level of the potential end users. From Sri Lankan context the income level and expenditure pattern are equally important when a new product or service is introduced to the market.

\section{Conceptual Framework}

The research methodology that best supports this study is, perhaps obviously, opinion research. This is accomplished by asking them via questionnaires. This research has used opinion poll based survey in order to collect primary data for the study. User questionnaire was used to collect primary data from a random sample of mobile users. This user level questionnaire was focused only on market acceptance of $3 \mathrm{G}$ mobile services. The questionnaire designed "To identify best practices for absorption and adaptation of 3G services" and "To assess the conduciveness of Immediate Environment of Transferor and Transferee for Smooth Transfer of 3G Technology "was distributed among the $3 \mathrm{G}$ project managers. In summary following methodologies were used to achieve the research objectives.

Sub objective 1 "Market acceptance of $3 \mathrm{G}$ services" - is achieved through a questionnaire survey.

Sub objective $2 \sim$ "To identify best practices for absorption and adaptation of 3G services" - is achieved through questionnaire survey with $3 \mathrm{G}$ Project Managers and interview with $3 \mathrm{G}$ project managers.

Sub objective $3 \sim$ "To assess the conduciveness of Immediate Environment of Transferor and Transferee for Smooth Transfer of 3G Technology- is achieved through questionnaire survey with 3G Project Managers

Main objective is achieved through amalgamating the three sub objectives.

\subsection{Research Model}

The conceptual model for the research was developed to achieve the research objectives. Part of the model is derived from "Compass Acceptance Model". Compass Acceptance Model is designed for the analysis and evaluation of user acceptance of mobile services. Compass Acceptance Model is used mainly to identify the variables related to the market acceptance. To the first sub objective, Market acceptance of $3 \mathrm{G}$ services, following variables were applied;
a) Perceived Usefulness
b) Perceived Ease of Use
c) Perceived Mobility
d) Perceived Costs
e) Customer attitude
f) Income level.

Explanation of the Compass Acceptance Model is discussed in literature review.

To the second and third sub objectives, a questionnaire is circulated with $3 \mathrm{G}$ project managers. The variables for the above objective were identified as follows;
a) Financial
b) Marketing
c) Regulatory
d) Technology
e) Project Implementation

Amalgamation of results of first three objectives will lead to the achievement of main objective of the research, "To Recommend Strategies for Transition to Third Generation Cellular Communication in Sri Lanka".

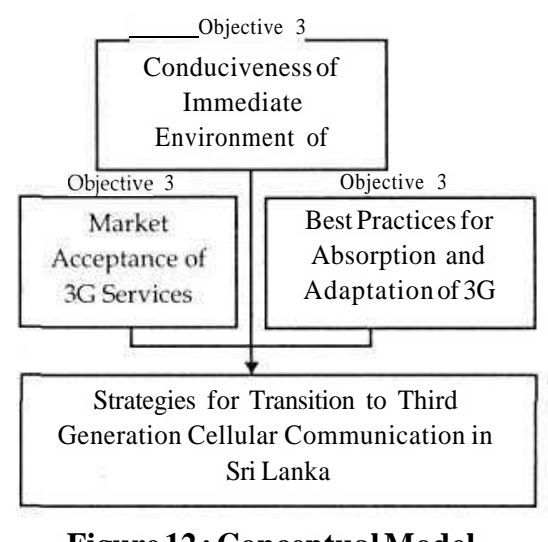

Figure 12 : Conceptual Model

Researchers have developed a conceptual model described in Figure 12, to achieve objectives of the research.

\subsection{Sources of Data}

Data collection for this research take place with two questionnaires prepared for the mobile phone users in Sri Lanka and $3 \mathrm{G}$ project managers. 
The popit ........ I this research for the first nitipulive - all the mobile phone users in Sri Ianka Throre sample is selected randomly. hiarvey I'M hitionnaires were distributed via eithails ana printed format. Random sampling was used in elec Issamples for the survey. More than 500 questionnaires were distributed among the mobiir phone users via both distribution thanels. I Irid copres were distributed among partiognts tor the survey and responded quем cumuinires were collected individually. The popuition for the second objective of the fesearch is the 36 ; project managers from ielecommurIKalion equipment vendors, Namely, Briesson Huawei Alcatel and idecommunu ation service provider, Dialog T, 1, I0m PLC.

fecondary data sources were also used to get ili anl data for this research. For secondary data ..... n sources such as reports and some publications are used on the chapter 2- literature aEi tion. On this most of global information was gathered through the Internet sources.

\subsection{Limitations of the Study}

I here are lew limitations that can be identified in an hieving the objective of this research I roject.

I III u ully on gathering information as the Mobile sector is having competitive information. The initial research methodology for the second objective, "To identify best practices for absorption and adaptation of $3 \mathrm{G}$ services", was through case study method and due to lack literature available the research methodology was changed to questionnaire based method.

Non availability of comprehensive literature on this topic for Sri Lanka, as 3G technology is very new to the island. Literature survey was done in international context, due to lack of local facts. Further, the importance of factors in Sri Lankan point of view may be different to that of global. As mentioned earlier, the amount of literature available is very minimal in local for this field of study. Though some research papers were available on the Internet, they are only available al a cost.
Knowledge of mobile users for high end services is very limited. Sri Lankan market is very widely used for basic telecommunication services and found difficulty in filling the questionnaire.

The user questionnaire was distributed among more than 500 users, but final feedback was only 212.

Although literature review provides many factors that are affecting the market acceptance of $3 \mathrm{G}$ services and best practices for absorption and adaptation of $3 \mathrm{G}$ services, only the most important factors were considered in the analysis for Sri Lankan context.

Researcher has prepared questionnaires in all three languages. The translation of technical words from English to Tamil and Sinhala was a limitation. For the words that are difficult to translate researchers have applied the English words. Understandability of the translated words and English words is limitation to the research.

\section{Survey Data Analysis}

\subsection{Sub Objective 1}

"To assess the market acceptance of $3 \mathrm{G}$ services in Sri Lanka". Researcher has used SPSS tool to carry out the data analysis. All the responses were given weightings as mentioned below for analysis. Below weighting is used to calculate the mean values.

4 - User strongly agree with the statement

3 - User agrees with the statement

2 - User partly agree with the statement

1 - User disagree with the statement

Table 2: Mean Value for Market Acceptance of $3 \mathrm{G}$ Services

\begin{tabular}{|l|c|c|c|c|}
\hline & $\begin{array}{l}\text { Mean } \\
\text { Values }\end{array}$ & Priority & Weightings \\
\hline $\begin{array}{l}\text { Market Acceptance } \\
\text { of 3G Services }\end{array}$ & $\begin{array}{c}\text { Perceived } \\
\text { Usefulness }\end{array}$ & 2.9975 & 1 & 0.29 \\
\hline 1 & $\begin{array}{c}\text { Perceived Ease } \\
\text { of Use }\end{array}$ & 3.2720 & 4 & 0.14 \\
\hline 3 & $\begin{array}{c}\text { Perceived } \\
\text { Mobility }\end{array}$ & 2.3296 & 6 & 0.05 \\
\hline 4 & Perceived Costs & 2.2579 & 2 & 0.24 \\
\hline 5 & $\begin{array}{c}\text { Customer } \\
\text { attitude }\end{array}$ & 2.8922 & 3 & 0.19 \\
\hline 6 & IncomeLevel & 1.4652 & 5 & 0.10 \\
\hline
\end{tabular}


These six variables will jointly build the "Market Acceptance of 3G Services". Contribution of each variable (weightings) was decided by an Industry expert from Dialog Telekom PLC. According to the expert view order of priority and weighting for each variables are as depicted in the Table 2.

The weighted average mean for "Market Acceptance of 3G Services" is 2.6628. Therefore it can be concluded that the Market acceptance of 3G services in Sri Lanka is at Moderate level.

\subsection{Sub Objective 2}

"To identify best practices for absorption and adaptation of $3 \mathrm{G}$ services"

Based on the questionnaire and interview with industry expert following best practices were identified in following areas.

\subsubsection{Finance}

a. Minimize cost of ownership (Maximize returns with minimal investments)

1. Common core network (Switching network) for $2 \mathrm{G}$ and $3 \mathrm{G}$ for packet and voice

2. More efficient Spectrum usage as large sum of money spent on $3 \mathrm{G}$ license

3. Increase usage by changing the visage pattern

4. Price $3 \mathrm{G}$ voice calls at a lower price than $2 \mathrm{G}$ and thereby inducing the subscriber to experience other services available in $3 \mathrm{G}$ network. This will result in increase Average Revenue Per User(ARPU)

5. Provide a common platform to integrate all new services (future proof)

6. 3G technology should be built on IP MPLS (Multi Protocol Label Switching) plat form to save transmission

b. Minimize costs of technology deployment

1. Implement softswitches to save power, space and implementation time

2. IP backbone to increase the bandwith efficiency. c. Payback period for $3 \mathrm{G}$ investment

1. $3 \mathrm{G}$ investment should be planned with 5 year payback period due to high license cost

\subsubsection{Project Implementation}

a. Best practices to accelerate time-to-market (Bypass the learning curve and speed up ability to generate revenue)

1. Outsource Implementation of $3 \mathrm{G}$ network to expedite network development.

2. Managed services for $3 \mathrm{G}$ networks from 6 months to 1 year period. Managed services is where completedevelopment and management of the network is contracted to the vendor with Service Level Agreements (SLA)

3. On the job and off the training of technical and customer care staff while the networkis beingimplemented

4. Hosted models for Value Added Services (VAS). Hosted model is where the server or the system that provides the VAS is located in within the premises of service developer or another service provider, locally or internationally.

b. Bestprojectmanagementpractices-Specific to $3 \mathrm{G}$

1. New technology management principle need to be integrated to Project management practices.

2. Interworking with multi vendor arrangement need to he given high priority

c. Recommended procurement method/ process.

1. Most recommended procurement method would be lo implement few pilot networks with selecled vendors and move towards the normal company accepted procurement procedures and policies 


\subsubsection{Marketing}

a. Best practices to Sustain competitive advantage with $3 \mathrm{G}$

1. Pricing for $3 \mathrm{G}$ services should be competitive as Sri Lankan market is price sensitive.

2. Pricing for data services should be same $2 \mathrm{G}$ and $3 \mathrm{G}$ network as subscriber does not see the service difference other than data rate.

3. Portfolio ofVAS, video, high speed data and contents should available to attract the market.

4. Good customer service and specially trained staff to support $3 \mathrm{G}$ related services

5. Marketing activities to educate customers

6. Seamless migration process for subscriber to move to $3 \mathrm{G}$ services.

b. Target market

1. Target market at the initial stage is Enterprise users, high-end customers and Small and Medium Enterprises

2. Youth segment can be targeted once more content and VAS are developed

\subsubsection{Technology}

a. Best practice in terms of technology and infrastructure for $3 \mathrm{G}$

1. Transmission backbone should be developed with IP MPLS capability to gain bandwidth efficiency

2. The network nodes that should be procured should be supporting $3^{\text {rd }}$ Generation Partnership Project (3GPP) $\mathrm{R} 5$ or above with radio network with High Speed Packet Access (HSPA) capability b. Best practices for service development with $3 \mathrm{G}$

1. The best practice for new service development is to outsource as most of the operators does not have the core competence on the service development

\subsubsection{Regulatory}

a. Best practices to overcome the pricing and coverage controls imposed by regulatory

1. In Sri Lankan context the coverage controls imposed by TRCSL is to cover three main cities in the country. Whereas some other countries have imposed country wide coverage. Hence in Sri Lanka 3G service providers are more or less relaxed from coverage controls.

2. There is no specific price controls imposed by TRCSL.

4.3 Sub Objective 3

"To assess the conduciveness of Immediate Environment of Transferor and Transferee for Smooth Transfer of 3G Technology"

Table 3: Mean Valuefor Conduciveness of Environment of Transferorand Transferee

\begin{tabular}{|c|l|l|l|l|}
\hline \multicolumn{2}{|c|}{} & $\begin{array}{l}\text { Mean } \\
\text { Values }\end{array}$ & Priority & Weightings \\
\hline 1 & $\begin{array}{l}\text { Knowledge and } \\
\text { capability of } \\
\text { Vendors }\end{array}$ & 2.5600 & 2 & 0.26 \\
\hline 2 & $\begin{array}{l}\text { Knowledge and } \\
\text { capability of local } \\
\text { staff }\end{array}$ & 3.1700 & 3 & 0.24 \\
\hline 3 & $\begin{array}{l}\text { Experience of } \\
\text { service providers } \\
\text { in the industry }\end{array}$ & 3.5000 & 1 & 0.27 \\
\hline 4 & $\begin{array}{l}\text { Infrastructure } \\
\text { Flexibility }\end{array}$ & 2.3300 & 4 & 0.23 \\
\hline
\end{tabular}

Fourvariables depicted in Table 3 willjointlybuild the "conduciveness of Immediate Environment of Transferor and Transferee for Smooth Transfer of 3G Technology". Contribution of each variable (weightings) was decided by an Industry expert fromDialog TelekomPLC. According to the expert view, order of priority and weighting for each variable are as depicted in the Table 3.The weighted average mean for "conduciveness of 
Immediate Environment of Transferor and Transferee forSmooth Transfer of 3G Technology" is 2.9073. Therefore it can be concluded that the conduciveness of immediate environment of transferor and transferor in Sri Lanka is at a better level.

\section{Strategies for Transition to Third Generation Cellular Communication in Sri Lanka}

\subsection{Corporate Strategy}

The decision to implement $3 \mathrm{G}$ services could be identified as corporate strategy for the company. The revenue made from $3 \mathrm{G}$ services will assist the organization to bridge the strategic gap, from a long term perspective.

Investment on $3 \mathrm{G}$ will pave the path to new business avenues and thereby adding value to the company. For example Mobile TV broad casting.

When the mobile service provider is making strategic shift in to new business areas with $3 \mathrm{G}$ technology the core competence in that business area might be lacking. Hence the strategy is to make strategic partnerships or acquisitions.

\subsection{Marketing Strategy}

Survey reveals that;

Market acceptance for 3G services in Sri Lanka is at moderate level. At the same time $3 \mathrm{G}$ awareness among the Sri Lankan mobile users is at the level of 67 percent. An effective advertising awareness campaign should be launched to create the need for $3 \mathrm{G}$ services for prospective corporate and non corporate customers. The advertisement and promotions should have following features.

a. Creating the need for $3 \mathrm{G}$ among mobile users

b. Creating awareness on $3 \mathrm{G}$ services. It should explain the services and educate the prospective $3 \mathrm{G}$ subscribers on how to use the services.

73.7 percent of the mobile users believe that the charges imposed by the operators for VAS is high. As the focus of $3 \mathrm{G}$ is more on data services the negative belief on charges on data services will get further strengthen, if the charging method is not transparent to the customers and reasonable consideration is not given. As the data rates are higher in 3G, service providers could implement low price high volume pricing strategy for data services. This pricing strategy will create a winwin situation as number of internet users is increasing in Sri Lanka (As per the literature review). Also the $3 \mathrm{G}$ voice calls could be charged at equal or lower price than $2 \mathrm{G}$ to attract more customers to $3 \mathrm{G}$ network.

Portfolio of VAS, Video, high speed data and contents should be available to attract the market and the best practice for new service development is to outsource as most of the operators does not have the core competence on the service development. The service providers should search for creative VAS developers in local and international market and to deliver fast hosted services could be launched.

64 percent of mobile users do not have handsets which support $3 \mathrm{G}$. At the same time 88 percent of the mobile users in Sri Lankans are with the opinion that $3 \mathrm{G}$ handsels are expensive. $3 \mathrm{G}$ service providers in collaboration or individually should introduce $3 \mathrm{G}$ handsets at a reasonable price to Sri Lankan market.

Interview with project managers reveals;

Good customer service with specially trained staff to support $3 \mathrm{G}$ related services is essential. Service providers should focus on developing highly trained staff dedicated for $3 \mathrm{G}$ customer support and the customer service centre should be placed in location with more convenient access and attractive. Also the customer service centre should be a sophisticated high tech show room where customers can experience and feel $3 \mathrm{G}$ services.

Target market at the initial stage is Enterprise users, high-end customers and Small and Medium Enterprises. Youth segment can be targeted once more content and VASs are developed. Hence existing corporate customers can be targeted by the service providers at the initial stage and then move to attract the youth segment once the fair number of VASs are developed. 
T. $\cdot$ mnless migration process for subscriber to move to 3G services as an important factor. The service providers should find ways to minimize effort taken by the customer to migrate from $2 \mathrm{G}$ to $3 \mathrm{G}$.

\subsection{Technology Strategy}

Survey reveals;

82 percent of the mobile users in Sri Lanka believe $3 \mathrm{G}$ will add value to the life. At the same time 86.5 percentages of the mobile users are concern on data security when using mobile applications and 95 percent of the mobile users believe that user friendliness of services is of most important for them to use new services. Following features need to be given high priority when developing new services or applications to increase the probability of success.
a. User friendliness
b. Data security
c. Value for money

Transmission backbone should be developed with IPMPLScapability togainbandwidthefficiency. $3 \mathrm{G}$ service provider could initially lease IP MPLS network from existing telecommunication infrastructure business companies. But they should make sure that they are developing their own network as the medium to long term strategy.

The network nodes should be supporting $3^{\text {rd }}$ Generation Partnership Project (3GPP) R5 or above with radio network with High Speed Packet Access (HSPA) capability. Service providers should give more emphasis on the version release of the equipments that they are procuring. Also they should be very concern on the road map of Research and Development of vendors, with time lines, to be ahead of leadership in the market.

The best practice for new service development is to outsource as most of the operators does not have the core competence on the service development. When selecting service developers more priority should be given on capability on developing services with User friendliness, Data security and Value for money.
To outsource implementation of $3 \mathrm{G}$ network to expedite network development. The service providers could outsource the network development to equipment vendors as they are much aware of their equipments and also they know better how to integrate their systems to other network elements. Further options such as managed services with agreed SLAs for a period of six month to one year is recommended.

On the job and off the training of technical staff are required while the network is being implemented. Proper technology transfer should take place in order to manage the $3 \mathrm{G}$ network after implementation. Hence the service providers at the stage of negotiation should pay more attention on knowledge transfer process and should specify the required training programs.

Interworking with multi vendor arrangement need to be given high priority. The providers should give more weight to the interworking criteria during technical evaluation of solution proposed by each vendor. They should investigate in to number of interworking successfully carried out in real networks and lab testingresults.

Most recommended procurement method would be to implement few pilot networks with selected vendors and select based on performance. Service providers could mitigate the risk of selecting the wrong vendor by implementing a Proof of Concept (POC) before launching the commercial network. POC should be carried out with few selected vendors and need to carry out a detail technical analysis on successful completion of project. And this networks need to be benchmarked against commercially available networks globally.

New technology management principles need to be integrated to project management practices. The project managers selected for $3 \mathrm{G}$ project should have fair knowledge on $3 \mathrm{G}$ technology or project manager should be given sufficient training on technology to handle the project. 


\subsection{Investment Strategy}

Common core network (Switching network) should be used for $2 \mathrm{G}$ and $3 \mathrm{G}$. Service providers could increase their ROIs and make use of the resources available to optimum level by adopting common for core $2 \mathrm{G}$ and $3 \mathrm{G}$.

Large sum of money spent on $3 \mathrm{G}$ license. Service providers should take more concern on usage of spectrum to the optimum level. This could be achieved by careful selection of geographical areas where prospective $3 \mathrm{G}$ users are densely populated.

Survey reveals that a very low percentage of mobile users (13.4 percent) are satisfied with 56 Kbps. 23.9 percentage of mobile users are requiring $512 \mathrm{Kbps}$ while 22.4 percentage mobile users are with very high expectation of $2 \mathrm{Mbps}$ data rate requirement. Hence, the service providers could customize data rate according to the customer requirement rather than providing a flat rate to all the customers. This way investors could make maximum use out their investment.

Implementation soft switches will save power, space and implementation time. By procuring soft switches service providers could maintain the system at lower cost.

\section{Conclusions and Recommendations}

\subsection{Conclusions}

This research has been carried out with the intention of finding the strategies to successful implementation $3 \mathrm{G}$ cellular communication projects in Sri Lanka. Selected population for the study is mobile users in Sri Lanka and 3G project managers.

Market acceptance of $3 \mathrm{G}$ services in Sri Lanka is at moderate level. But this condition will change over period of time with demand for bandwidth hungry application. There is positive growth in internet users and this will have positive impact on demand for $3 \mathrm{G}$ services.

New product or service will succeed or fail depending on the customer experience. It is what they feel or think matters. The implementation should prioritize the delivery of benefit rather than clever technology.
Conduciveness of immediate environment of transferor and transferee in Sri Lanka is at better level. Hence Sri Lankan mobile service providers are technically in a better position to absorb the technology.

3G for Sri Lanka is best suited at this time to reduce the digital divide and to use as a tool to fill the strategic gap by service providers. The best practices were derived from industry experts (3G project Managers) and these guidelines could be practiced by any of the mobile service provider in Sri Lanka as well as international operators. The strategies were formulated based on the survey results and interview with industry experts. Thestrategies were developed from four perspectives;
a. Corporate Strategy
b. Marketing Strategy
c. Technology Strategy
d. Investment Strategy

\subsection{Recommendations}

Though the strategies are listed with four perspectives, during the implementation phase all four categories of strategies need to be integrated as strategies listed are linked to each other.

A strategic partner for network implementation is essential for the delivery of reliable network on time. Following factors need to be considered in selecting the vendor [10].

a. Long-term support for lifecycle cooperation and continues innovation

b. Flexible customization with cost efficiency

c. Execute and finish strategy on time

d. Decrease the risk of system integration

e. Successful experience sharing to reduce the business risk

Project management is crucial in telecommunication business to be in the market leader position. A dedicated project management team should be formulated to deliver the scope of the $3 \mathrm{G}$ project on time. 
A Study from National Technical University of Athens reveals that following migration path is suited for $3 \mathrm{G}$ service migration.

Step 1 - Common backbone network

Step 2 - Some voice and more data

Step 3 - Everything over data

Craig Scollick, Cerillion Technologies Implementation director recommends that once the ideal $3 \mathrm{G}$ products have been designed, building blocks needed to bill these correctly must be properly defined. Working closely with the billing system supplier is a key in making this a success

\section{References:}

[1]http://www.gsmworld.comVisited 10thJune 2007

[2] Chen, J. C., Zhang, T., IP-Based NextGeneration Wireless Networks: Systems, Architectures and Protocol, John Wiley and Sons, Inc., 2004, p.413.

[3] http://www.itu.int 2006 Visited 20th May 2007

[4] www.simonwoodside.com Visited 20th May 2007

[5] "Paul Rasmussen.."What's in a Name". Mobile Frontiers, Feb/Mar 2005,Issue 4

[6] http://www.trc.gov.lk Visited 20thJune

[7] www.adb.org Visited 10th May 2007

[8] Daily Mirror ."Deriving socio-economic dividends from mobile communications"., 30th September 2007

[9] Markus Hirschmeier and Jens Wehrmann" The Compass Acceptance Model for the Analysis and Evaluation of Mobile Services" International Journal of Mobile Communications,2004, Vol. 2, No.3 p, $248-259$

[10] www.huawei.com visited 19th July 2007 